\title{
Evaluation of a ray-tracing canopy light model based on terrestrial laser scans
}

\author{
Sebastian Bittner, Sebastian Gayler, Christian Biernath, Jana Barbro Winkler, \\ Stefan Seifert, Hans Pretzsch, and Eckart Priesack
}

\begin{abstract}
The local light regime within the tree canopy is crucial information for modeling water, carbon and nutrient cycling, and vegetation-atmosphere interactions. We tested the performance of a new model to simulate the light environment in the canopy of a juvenile beech stand under controlled light conditions. The canopy architecture was determined using a terrestrial laser scanner to derive a three-dimensional voxel representation. Depending on whether a voxel represents stem biomass, leaf biomass, or air, different attributes of light are assigned to the voxel. The model combines a representation of the canopy as three-dimensional cells (voxels) with a fast ray tracing algorithm that calculates the absorbed fraction of incoming photosynthetic active radiation (PAR). The simulated light regime of the stand was compared with measurements of the PAR regime inside the canopy (model efficiency Nash-Sutcliffe efficiency $(\mathrm{NSE})=0.88$, root mean square error $\left.(\mathrm{RMSE})=124 \mu \mathrm{mol} \mathrm{m} \mathrm{m}^{-2} \mathrm{~s}^{-1}\right)$ and the soil surface $(\mathrm{NSE}=0.65$, RMSE $=$ $\left.22 \mu \mathrm{mol} \mathrm{m} \mathrm{m}^{-2} \mathrm{~s}^{-1}\right)$. The model needs two input parameters, the edge length of the voxels and the light attenuation coefficient of the voxels. The best simulation results were achieved at a voxel size of $0.03 \mathrm{~m}$. For model calibration, only measurements of the light fraction that reaches the soil surface are needed. The good agreement of the simulated and the measured light regime together with the fast computation by the ray tracing algorithm suggest that the model is also applicable to simulate the light regime of natural forests under variable light conditions.
\end{abstract}

Résumé. Le régime de la lumière locale au sein de la canopée des arbres est une information essentielle à la modélisation des cycles de l'eau, du carbone et des éléments nutritifs, ainsi que des interactions entre la végétation et l'atmosphère. Nous avons testé les performances d'un nouveau modèle de simulation de l'environnement de la lumière dans la canopée d'un peuplement de jeunes hêtres dans des conditions de lumière contrôlées. L'architecture de la canopée a été déterminée à l'aide d'un scanner laser terrestre permettant de dériver une représentation tridimensionnelle en voxels. Différents attributs de lumière sont affectés au voxel selon que ce dernier représente la biomasse des troncs, la biomasse foliaire ou l'air. Le modèle combine la représentation de la canopée sous forme de cellules tridimensionnelles "voxels» avec un algorithme rapide de lancer de rayon qui calcule la fraction absorbée de rayonnement photosynthétiquement actif «PAR » entrant. Le régime de lumière simulé du peuplement a été comparé à des mesures du régime PAR à l'intérieur de la canopée (efficacité du modèle NSE $=0,88, \mathrm{RMSE}=124 \mu \mathrm{mol} \mathrm{m}^{-2} \mathrm{~s}^{-1}$ ) et à la surface du sol (NSE $=0,65$ et un RMSE de $\left.22 \mu \mathrm{mol} \mathrm{m} \mathrm{m}^{-2} \mathrm{~s}^{-1}\right)$. Le modèle nécessite deux paramètres d'entrée: la longueur d'arête des voxels et leur coefficient d'atténuation de la lumière. Les meilleurs résultats de simulation ont été obtenus sur une dimension de voxel de $0,03 \mathrm{~m}$. Seules des mesures de la fraction de lumière qui parvient à la surface du sol sont nécessaires pour l'étalonnage du modèle. La bonne concordance entre le régime de la lumière simulé et celui mesuré en appliquant le calcul rapide par l'algorithme de lancer de rayon montre que le modèle peut être appliqué également pour simuler le régime de la lumière de forêts naturelles dans différentes conditions de lumière.

\section{Introduction}

A good estimation of the local light regime within tree canopies is crucial information needed in models of the cycles of water, carbon, and nutrients in forest ecosystems and of the interaction between the vegetation and the atmosphere. In these models, interception and absorption of light are sensible input variables to simulate functions such as transpiration and photosynthesis. Several models are based on a stand-level approach and neglect local

Received 10 May 2011. Accepted 3 August 2012. Published on the Web at http://pubs.casi.ca/journal/cjrs on 20 December 2012.

Sebastian Bittner, Sebastian Gayler, Christian Biernath', and Eckart Priesack. Institute of Soil Ecology, Helmholtz Zentrum München, Ingolstädter Landstraße 1, 85764 Neuherberg, Germany.

Sebastian Gayler. WESS - Water \& Earth System Competence Cluster, Hölderlinstr. 12, 72074 Tübingen, Germany.

Jana Barbro Winkler. Research Unit Environmental Simulation (EUS), Institute for Biochemical Plant Pathology, Helmholtz Zentrum München, Ingolstädter Landstraße 1, 85764 Neuherberg, Germany.

Stefan Seifert and Hans Pretzsch. Chair of Forest Yield Science, Center of Life and Food Sciences Weihenstephan, Technische Universität München, Hans-Carl-von-Carlowitz-Platz 2, 85354 Freising, Germany.

${ }^{1}$ Corresponding author (e-mail: christian.biernath@helmholtz-muenchen.de). 
inhomogeneity of the canopy like gaps or leaf clusters (Bossel, 1996; Hoffmann, 1995) or include an up-scaling from individual trees to consider light inhomogeneities in a parametric way (Oker-Blom et al., 1989; Larsen and Kershaw Jr., 1996). However, as inhomogeneities can have large effects on the local light regime (Castro and Fetcher, 1999; Whitehead et al., 1990) more advanced models use explicit three-dimensional representations of the canopy.

Explicit geometrical models have approached the representation of the canopy in different levels of complexity. The use of three-dimensional virtual trees generated from growth simulation rules such as L-Systems (Allen et al., 2005; Da Silva et al., 2008; Disney et al., 2006; Roupsard et al., 2008; Lamanda et al., 2008; Sinoquet, 2007; Parveaud et al., 2008; Hemmerling et al., 2008) provides information on the position and orientation of leaves and can be used for raytracing algorithms, for example by using the leaf orientation for the calculation of scattered light. The disadvantage of complex canopy models is the high demand of input data that are often difficult to obtain.

Therefore, some models approximate the shape of the canopy by simple geometrical bodies (such as ellipsoids, frustrums, or cylinders (Widlowski et al., 2006; Brunner, 1998; Green et al., 2003; Kobayashi and Iwabuchi, 2008; Courbaud et al., 2003; Gayler et al., 2006)) or hulls (Cescatti, 1997; Da Silva et al., 2008). In these models, the leaf area is distributed inside the bodies either constantly or based on physiological observations. The light distribution within the canopy can then be calculated by the radiative transfer equation (Ross, 1981) with the scattering being often neglected leading to a Beer's law of light attenuation (Monsi and Saeki, 1953). An alternative approach to represent the structure of a canopy in a model is to use a discretization of the space into cubical volume elements, called voxels (Kimes, 1984; Cohen and Fuchs, 1987; Gastellu-Etchegorry et al., 2004; Perttunen et al., 2007; Van der Zande et al., 2009), that are either filled by elements of the vegetation or not. Light attenuation within the canopy can then be calculated by tracing the light rays that penetrate the canopy and applying Beer's law for each filled voxel. By decreasing the size of the voxels a more precise determination of the space occupied by the vegetation can be achieved. But, on the other hand, the question arises if the original assumptions leading to the Beer's law of light attenuation are still valid, because the assumption of infinitesimal small phytoelements randomly distributed inside the single voxels does not hold if the voxel size is similar to the leaf size of the plant (Knyazikhin et al., 1997; Myneni et al., 1989; Govaerts and Verstraete, 1998). In this case, the extinction coefficient of the simple exponential formula of light attenuation cannot be referred to physical or geometrical properties of the vegetation. In this study the light attenuation coefficient was interpreted as a voxel-based model input parameter that had to be calibrated to the specific stand.
Light models that describe the canopy by an envelope that attenuates light according to a Lambert-Beer law often include the measured leaf angle distribution and a leaf distribution function in the expression for the light attenuation factor (Baldocchi and Harley, 1995). This is important when the leaves are clumped in old-growth forests and when the expression for the light attenuation factor is derived by physical and geometrical approaches. Here the question arises whether an empirical and constant light attenuation factor used in this study is adequate to simulate the light regime. Analyzing digitalized and simulated tree architectures Sinoquet et al. (2005) could show that the clumping effect should be included in models that work on coarse envelopes of the canopy, but they can be neglected if a voxel representation of the canopy with a small voxel size is used. We found that decreasing the voxel size generally increases the fraction of the inhomogeneity of the spatial leaf distribution accounted for by the space division into voxels with the optimal voxel size similar to the leaf size. Wang (2003) states that a constant light attenuation factor, which is independent of the leaf angle distribution and leaf clumping, is accurate if the model considers the direct and the diffuse radiation separately.

An analytical derivation of the voxel extinction coefficient based on information on the forest structure might be helpful to generalize the model input values to other species and stands without further calibration. However, these structural data are often laborious to obtain and have an uncertainty themselves. Therefore, the use of a single empirical extinction coefficient parameter that can be derived from light measurements or sap flux measurements (Bittner et al., 2012b) could help to advance functionalstructural models. This could be the case especially when the light distribution is an input of other submodels such as the photosynthesis of stomatal models and when the principles of light distribution inside canopies are not in the focus of the research.

Because of improvements in the light detection and ranging (LiDAR) technique in recent years, terrestrial laser scanners (TLS) make it possible to retrieve the structural data of forests in high detail. Moorthy et al. (2008) were able to retrieve the leaf area index (LAI), gap fraction, and clumping index from laser scans in a laboratory experiment with a tree of a similar height as the beeches used in our experiment. Structural parameters such as the total LAI and foliage profile have also been retrieved in natural forest stands using TLS (van Leeuwen and Nieuwenhuis, 2010). Estimations of the directional canopy gap probability, the probability that a beam will not intercept a canopy element in a given direction, can be retrieved from TLS data and are used as a measure of the spatial light regime (Jupp et al., 2009; Ni-Meister et al., 2008; Danson et al., 2007; Huang and Pretzsch, 2010). Advances in the interpretation of the TLS data and algorithms for the computing of the retrieved data offer possibilities for applications in functionalstructural modeling of the water and nutrient cycle of trees 
(Van der Zande et al., 2009; Todd et al., 2003; Van der Zande et al., 2010). Todd et al. (2003) showed that laser scanning is a promising technique for the estimation of light regime by testing the simulations with measurements of photosynthetically active radiation (PAR) at the forest surface of a sugar maple (Acer saccharum L.) stand.

The aim of the present study was to evaluate the performance of a modeling approach based on a voxel representation of the canopy. This was based on TLS measurements of trees in combination with a fast raytracing algorithm that calculates the attenuation of incoming PAR. In this approach, the space containing the trees is divided into voxels and every voxel that contains at least one point of the TLS point cloud is assumed to be part of the canopy. The ray-tracing algorithm represents the incoming light rays as lines that decrease in intensity according to Beer's law every time an occupied voxel is intersected. To evaluate the accuracy of the simulated light regime, we measured the light distribution in a juvenile beech stand (Fagus sylvatica L.) under controlled light conditions in a greenhouse and used our model to simulate the special situation of this experimental setup. The deviation between simulated and measured light regime in the stand was assessed by different statistical criteria. We analyzed the sensitivity of the model with respect to the input parameters of the model, the edge length of the voxels, and the light absorption coefficient. Finally, we analyzed the computational performance of the model and discuss whether the model is transferable to natural adult forests under variable light conditions.

\section{Methods}

\section{Experimental beech stand}

Nine containers, each planted with eight 4-year-old beech trees, were set up in a greenhouse in a way that a dense canopy was achieved. The 72 trees occupied a ground area of about $1.25 \mathrm{~m} \times 1.45 \mathrm{~m}$. The highest tree was $1.07 \mathrm{~m}$ tall, and the mean height of the stand was $0.58 \mathrm{~m}$. The stem diameters $0.05 \mathrm{~m}$ above the ground varied between $0.0036 \mathrm{~m}$ and $0.0113 \mathrm{~m}$. Subsequent to the TLS measurements (detailed in "Terrestrial laser scanner setup") the leaves were collected and the total LAI was determined to be 2.5. Measurements of the leaf angle distribution allowed an estimation of the vertical projection of the leaf area per square metre of $2.2\left[\mathrm{~m}^{2} \mathrm{~m}^{-2}\right]$.

\section{Lighting and PAR measurements}

A grid of nine $400 \mathrm{~W}$ metal halide lamps (Osram HQI-TS 400 W/D, Osram GmbH, München, Germany) in combination with projectors (Lightstream Box-type Maxi 721091.784, RZB GmbH, Bamberg, Germany) was installed above the canopy to provide a constant incoming light intensity. The distance of the lamps to the soil surface of the beech stand was $1.35 \mathrm{~m}$.

Under these lighting conditions, PAR was measured using the Li-190 Quantum Sensor (LI-COR Biosciences, Lincoln, Neb.) and the light intensity of the electromagnetic spectrum ranged from $400-700 \mathrm{~nm}$. On the soil surface beneath the canopy we measured the PAR values at 783 positions on a grid layout with a distance of $5 \mathrm{~cm}$ between two measurement positions. For a three-dimensional grid layout with a $20 \mathrm{~cm}$ distance between the measurement points, PAR was also measured at layers at a distance of $0,20,40$, and $60 \mathrm{~cm}$ from the soil surface at 224 measurement points.

\section{Terrestrial laser scanner setup}

To get information about the shape and spatial distribution of leaves and twigs of the sample trees we used a Riegl Z420i terrestrial laser scanner. This scanner has a range measurement standard deviation of $1 \mathrm{~cm}$ and a beam divergence of $0.25 \mathrm{mrad}$. It operates on the principle of time-of-flight measurements, which means it counts the time between sending out a laser impulse and the detection of the returned echo. The scanner is able to scan a panoramic $360^{\circ} \times 80^{\circ}$ field with one setup. The angular spacing between two measurements was set to about $0.06^{\circ}$ at a resolution of $0.002^{\circ}$, which resulted in an average point distance of $2 \mathrm{~mm}$ in a $2 \mathrm{~m}$ distance. To gather a complete three-dimensional point cloud of the beech group scans were made from four positions at ground level and at seven positions from about $1 \mathrm{~m}$ above ground level (Figure 1). The setup positions were distributed around the tree groups to scan from many directions with a distance of approximately 2-3 $\mathrm{m}$ to the center of the tree group. The size of the greenhouse and the minimal distance of the laser scanner to the scene did not allow a perfectly symmetric layout of the scan positions. All scan setup positions were referenced in a local coordinate system using reflectors and reference targets with a positional average standard deviation of less than $4 \mathrm{~mm}$ for all coordinate axes. As the scanner is able to detect the first or last returning pulse, the first pulse was used to ensure that small twigs were also detected by the scanner. In addition to the distance measurements, photographic images from a digital camera attached to the scanner were acquired. To be able to simulate the light conditions adequately, the coordinates of the lamps were extracted manually from the laser scans.

\section{Canopy and light model}

The canopy model architecture was solely retrieved from TLS measurements using the cloud of three-dimensional points that result from reflections of the laser beam at the surface of the trees. The virtual space was divided into threedimensional small cubes (voxels) and the canopy was represented by a set of $m$ voxels $V=\left\{v_{1} \ldots v_{m}\right\}$ containing 


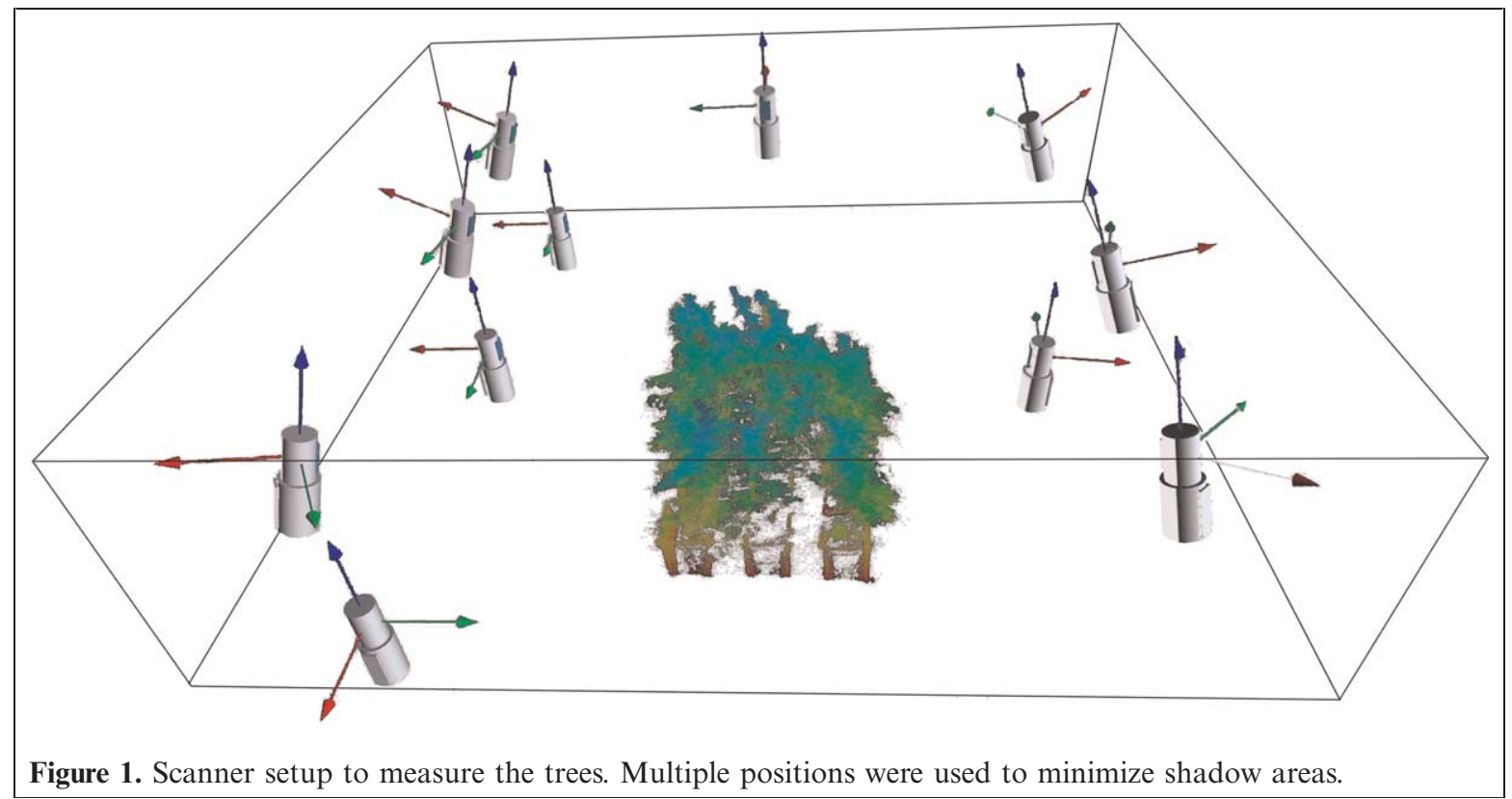

at least one point of the TLS reflection points. The number (n) of the voxels that the space is divided into will further be referred as the resolution of the voxel representation. To optimize the memory usage and the computational time (details in "Performance"), the implementation was based on the octree division of space (Wilhelms and Van Gelder, 1992). The space was represented by a threedimensional cube and is recursively subdivided into eight octants of the same size. The number of voxels equals the number of the smallest cubes that result from the partitioning and is given by

$n=\left(2^{p}\right)^{3}, p \in \mathbb{N}$

where $p$ is the number of subdivisions of the space by the octree algorithm.

The octree division of space optimizes the use of memory by dividing the space into voxels of different size. A threedimensional region that does not contain any biomass was represented by a large cube with one parameter set, and regions containing biomass were represented by smaller voxels according to the defined resolution.

The incoming light was represented by line segments $\left(R_{i}\right)$ each defined by a starting point $\left(S_{i}\right)$, an ending point $\left(E_{i}\right)$, and a starting intensity $\left(I_{0}^{i}\right)$. The line segments are herein referred to as rays. Assuming the greenhouse lamps behaved as point light sources, the starting points of the rays were the positions of the lamps. This resulted in a total number of $9 \cdot m$ rays, as the end points of the rays from each of the 9 lamps are the central points of the $m$ voxels that represent the canopy. The light regime was simulated at the positions of the PAR sensors that could be located at voxels not obtained by the canopy. The $I_{0}^{i}$ was calculated by setting the position of the lamp into the origin of a coordinate system and then using the solid angle that the voxel $i$ subtended. The azimuth and elevation of the ray were used considering a nonhomogeneous spatial light distribution of the lamps in combination with the projectors given by the retailer in the EULUMDAT format (RZB GmbH, Bamberg, Germany). The coupling with the canopy model was done by calculating the set of voxels $A^{i}=\left\{a_{j}^{i}\right\}$ with $j \in\left[1 \ldots n_{i}\right]$ and $a_{j}^{i} \in\left\{v_{1} \ldots v_{m}\right\}$ that intersect with an arbitrary ray $R_{i}$. We applied the Amanatides-Woo algorithm (Amanatides and Woo, 1987) for three dimensions for this step. Then the intersection length $d_{j}^{i}$ of the ray $R_{i}$ and every intersected voxel $a_{j}^{i}$ was calculated analytically. The attenuation of light could then be calculated at every position in the canopy using Beer's law

$I(d)=I_{0}^{i} \exp (-k d)$

with the incoming light intensity above the canopy $I_{0}^{i}\left[\mu \mathrm{mol} \mathrm{m}^{-2} \mathrm{~s}^{-1}\right]$, the attenuation coefficient $k\left[\mathrm{~m}^{-1}\right]$, and the attenuation length $d[\mathrm{~m}]$ that is the sum of the intersection length of the intersected voxels between the starting point of the ray and the regarded position. Thus, the light intensity $I_{j}^{i}\left[\mu \mathrm{mol} \mathrm{m}^{-2} \mathrm{~s}^{-1}\right]$ after intersecting the voxel $a_{j}^{i}$ is given by

$I_{j}^{i}=I_{0}^{i} \exp \left(-k \sum_{c=1}^{j} d_{c}^{i}\right)$

The value for the attenuation coefficient $k$ was kept constant for all voxels in this study. However, the model would be capable of dealing with voxels that are unequally parametrized allowing a division into sun and shade leaves for example.

We further included an optional first-order isotropic scattering of light on leaves and other plant structures. For every canopy voxel, we used Equation (3) to calculate the light that does not transmit the voxel freely and is either absorbed or scattered. The partitioning into absorption and 
scattering is given by the scattering coefficient. In that way every illuminated voxel acts as a secondary light source in the scattering model. The targets of the secondary light sources are every voxel of the canopy and the layers that are interesting for the light regime comparison with measurements. The intensity of these secondary light rays are given by the total amount of scattered light by the source multiplied with the solid angle of the target in relation to the voxel scattering the light.

\section{Calibration criteria}

Three statistical criteria were used to compare the simulated values of PAR $m_{i}$ with the $n$ measured values $o_{i}$.

Deviations from the measurements are estimated by the root mean square error (RMSE) in total values $\left[\mu \mathrm{mol} \mathrm{m}^{-2} \mathrm{~s}^{-1}\right]$ with

$\mathrm{RMSE}=\sqrt{\frac{1}{n} \sum_{i=1}^{n}\left(o_{i}-m_{i}\right)^{2}}$

The Nash-Sutcliffe efficiency (NSE) is related to the RMSE and defined by Nash and Sutcliffe (1970)

$\mathrm{NSE}=1-\frac{\sum_{i=1}^{n}\left(o_{i}-m_{i}\right)^{2}}{\sum_{i=1}^{n}\left(o_{i}-\bar{o}\right)^{2}}$

where $o$ is the mean value of the observed values. The NSE values are dimensionless and can take values from $-\infty$ to 1.0. A NSE value of 1.0 is given for a perfect match of simulation and observation, if NSE $\leq 0$, the model is not better than a model that uses the observed mean as a predictor.

The third criterion is the normalized root mean square error (NRMSE). It is given as the ratio of the RMSE to the data range

$\mathrm{NRMSE}=\frac{\mathrm{RMSE}}{o_{\max }-o_{\min }}$

with $o_{\max }$ and $o_{\min }$ the largest and lowest observed values, respectively.

\section{Results and discussion}

\section{Measured and simulated PAR}

The measured PAR intensities at the surface ranged from 6 to $296 \mu \mathrm{mol} \mathrm{m} \mathrm{m}^{-2} \mathrm{~s}^{-1}$. The relative error of the PAR measurements was estimated statistically to be 0.10 and was based primarily on errors of the positioning of the quantum sensor at the grid nodes. Additional errors occurred at positions where the sensor was close to the tree stem, branches, or leaves. At these locations small variations (millimetres) of the sensor position lead to sensible variations of the measured value up to $25 \%$. To elicit effects of data noise due to measurement errors, the measured values were smoothed before the comparison with the simulated values. A Gaussian kernel was used for the smoothing of the values at the ground according to a Gaussian semivariogram model of the measured data. The data were not smoothed for the three-dimensional $0.2 \mathrm{~m}$ grid, as the distance between two measurement points was too large with respect to the co-variation length of the local light regime.

The voxel ray tracer was able to reproduce the light regime with canopy depth (Figure 2) and at the soil surface with respect to the position of bright spots and shadowed areas (Figure 3) as well as the total values of light intensity. The attenuation coefficient was calibrated to $k=2.1 \mathrm{~m}^{-1}$. For the 783 measurement points at the soil surface, the model performed with NSE was 0.65 , RMSE was $22 \mu \mathrm{mol} \mathrm{m}{ }^{-2} \mathrm{~s}^{-1}$, and NRMSE was 0.11 . Without smoothing the NSE was 0.56. At the three-dimensional grid NSE was 0.88 , RMSE was $124 \mu \mathrm{mol} \mathrm{m}{ }^{-2} \mathrm{~s}^{-1}$, and NRMSE was 0.10 . Separated into the single layers the NSE values were 0.25 for the layer at soil surface, 0.31 for the layer at $0.2 \mathrm{~m}$ height, 0.50 for the layer at $0.4 \mathrm{~m}$, and 0.55 for the layer at $0.6 \mathrm{~m}$. We interpreted the values as a good match of the simulation and the measurement, because in addition to the intrinsic simplifications of the voxel ray tracer approach other factors contributed to a deviation of simulation and measurement: (i) PAR measurement errors occurred as discussed above and (ii) woody compartments such as stem or branches also contributed points to the laser scan and to the voxel representation of the tree.

The quality of the model could be further increased by separating nongreen voxels from leaf voxels to exclude a transmission of light through woody parts. Applying this correction Moorthy et al. (2008) were able to improve the estimation of LAI from laser scanned data at an experimental setup.

We also analyzed the influence of first-order scattering by keeping the transmissibility of the voxels constant and

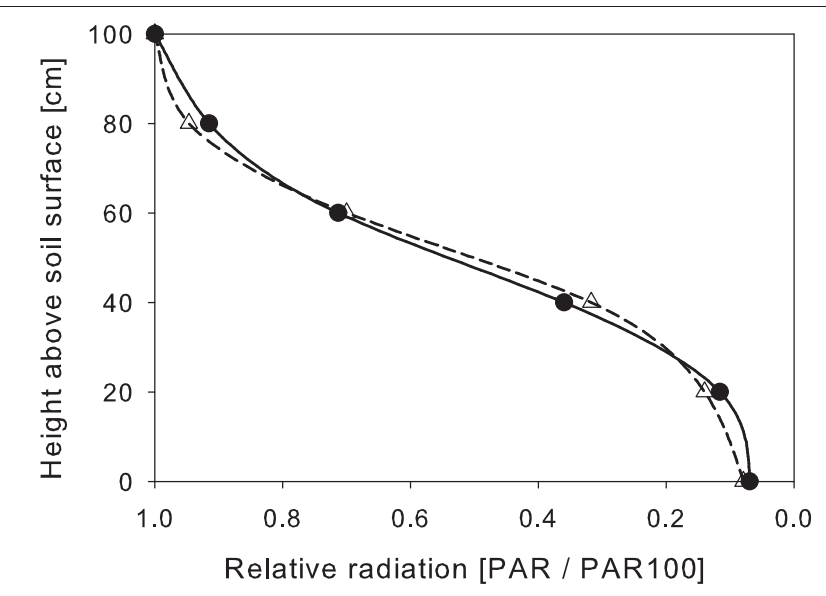

Figure 2. Simulated and measured vertical PAR regime in fractions of the PAR above the canopy $100 \mathrm{~cm}$ above the soil surface (PAR100). 


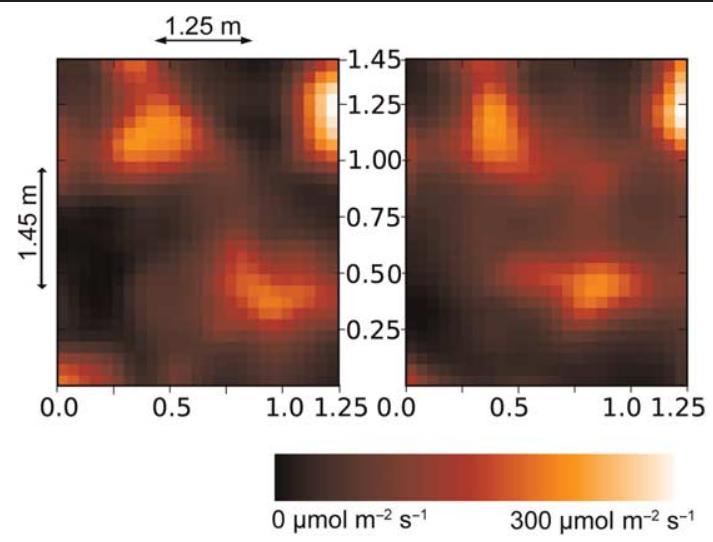

Figure 3. Smoothed measured (left) and simulated PAR values (right) at soil surface beneath the canopy of the artificial beech stand.

assumed a scattering of the light that does not transmit the voxel freely. First-order isotropic scattering increases the simulated light regime at the sensor positions when the transmissibility is kept constant. Using a scattering coefficient of 0.10 (De Pury and Farquhar, 1997) and not changing the value of $k$, the PAR intensity was increased by $4.3 \%$ at the surface in comparison with the calculations without scattering. The RMSE was decreased only marginally at all canopy layers even if $k$ was recalibrated. Because of the minor impact of the isotropic first-order scattering on the modeled light regime as a result of the low PAR scattering coefficient of leaves, we conclude that the simulation of the light regime can be simplified by neglecting the scattering of PAR at the voxels. This is consistent with a study (Wang, 2003) that states that neglecting light scattering is an acceptable simplification for modeling the distribution of PAR within plant canopies. By comparing three different canopy radiation models Wang (2003) concluded that a simple Beer's absorption law can be used to estimate the absorbed visible radiation. However, the situation may be different for oldgrowth forest stands on days with a high fraction of diffuse sky radiation. It was observed that the relative light intensity below the canopy was higher below the canopy under these conditions because of the effects of scattering. Scattering effects will have a higher impact on the simulated light regime when wavelengths at near-infrared or ultra-violet are simulated because their reflection coefficient is higher than the reflection coefficient for PAR (De Pury and Farquhar, 1997).

\section{Sensitivity analysis}

The input parameters of the model are the spatial resolution of the scene, given by the total number of voxels $n$ or the edge length $L[\mathrm{~m}]$ of the voxels and the light attenuation coefficient $k\left[\mathrm{~m}^{-1}\right]$. Figure $\mathbf{4}$ shows the visualization of the experimental canopy for different resolutions of the voxel space. The sensitivity of the model to the spatial resolution was analyzed by computing NSE between measured and simulated PAR at the soil surface for different values of $n$. For the resolutions $16^{3}, 32^{3}, 64^{3}, 128^{3}, 256^{3}$, and $512^{3}$ the NSE values were $0.08,0.46,0.64,0.60,0.50$, and 0.38 , respectively.

The model shows an optimum NSE for an edge length of $0.031 \mathrm{~m}$. The decrease for higher $L$ can be explained by an insufficient representation of the canopy by large voxels. Decreasing NSE at high resolutions are due to laser scanner input data errors. Outer trees shaded the laser rays, which resulted in decreasing point cloud densities to the center of the beech stand. These differences of the point cloud density resulted in a different density of voxels in the model only for high resolutions. For low resolutions with larger voxels the effect was leveled out, because a voxel was defined to be part of the canopy if at least one point of the laser scan was inside. The total number of laser scanned points lying inside of a voxel was not included in the model and did not affect the absorption coefficient of the voxel. This simple approach may be improved by the possibility of the model to assign every voxel a distinct absorption coefficient that may be correlated to density of laser scanned points lying in that voxel.

Interestingly, in the region of the optimal value of $L$ the slope of the model efficiency curve was low indicating a robust reaction of the model to changes of $L$. For values

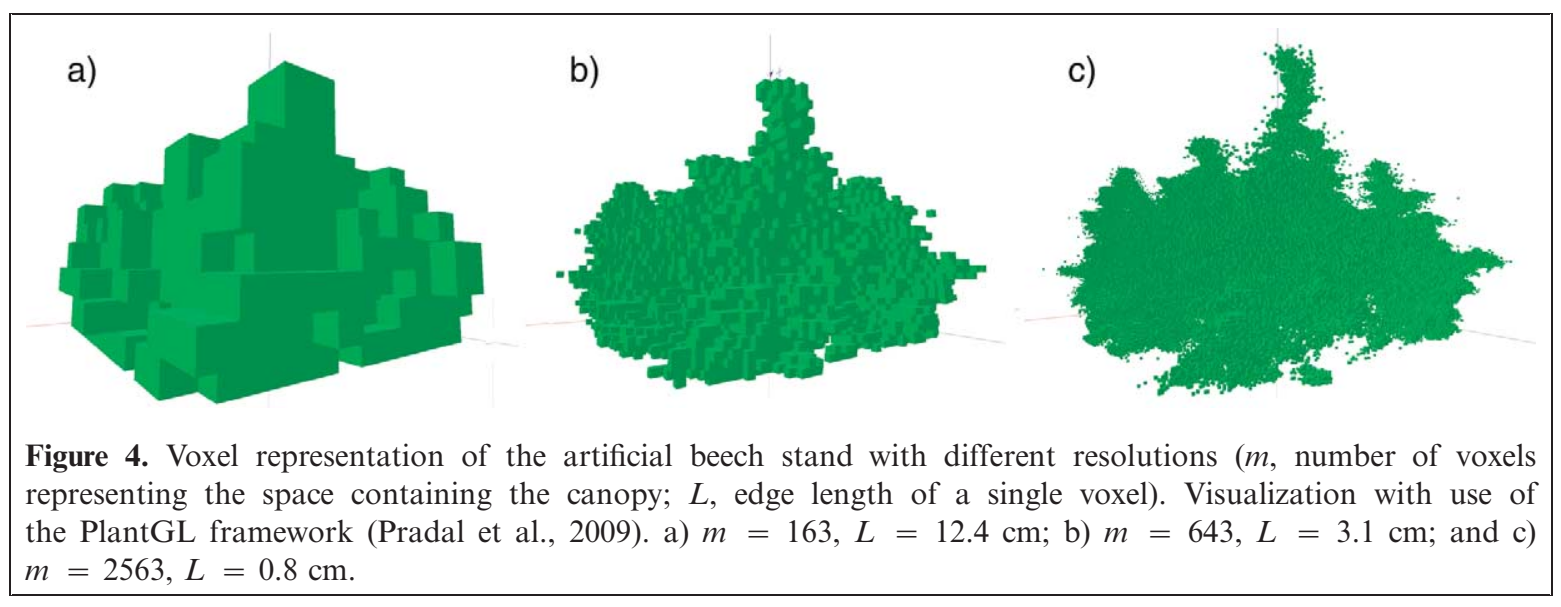


between $0.008 \mathrm{~m}$ and $0.031 \mathrm{~m}$ the model efficiency was larger than 0.5 . This behavior is a good indication for the transferability of the light model to further applications in natural and adult forests. Obviously the geometry of the canopy can be represented adequately if the intrinsic resolution of the TLS data is not exceeded by the voxel size and, on the other side, if $L$ is small enough to represent the canopy structure with respect to leaf clustering and gaps. A more accurate calibration of $L$ to laborious and expensive field measurements that are not easy to obtain may be not necessary.

For the second input parameter, the attenuation coefficient $k$, the situation is different. We use $k$ as a calibration parameter of the model and do not give a physical or geometrical description for the calculation of $k$. The values of $k$ are also dependent on the voxel size $L$. The calibrated values of $k$ were smaller for large voxels. This can be explained geometrically by the space occupation factor of the canopy in voxel space for different resolutions. For applications of the light model, the parameter $k$ has to be calibrated to the fraction of light reaching the forest soil surface or measurements of other variables related to light regime.

\section{Performance}

At a resolution of $n=512^{3}$ the canopy occupied about $m=10^{6}$ voxels. For every voxel the incoming direct light originating from the nine lamps was calculated resulting in a total number of $9 \times 10^{6}$ rays. On a single processor machine (2.3 Ghz, 2 GB RAM) the computational time was about 4 minutes. At a resolution of $n=64^{3}$ the canopy occupied about $3.3 \times 10^{4}$ voxels and the computational time was about two seconds. The algorithm is therefore fast enough to simulate the variable light regime under field conditions that are affected by changes of the sun position and of meteorological factors, such as cloudiness, described by 11 standards for spatial sky luminance models. Moreover, a parallelization of the algorithm can be easily achieved because the calculation of the intersection of a ray and the canopy is independent for individual rays. Including a firstorder scattering increases the amount of rays to be of $O\left(\mathrm{~m}^{2}\right)$ and thus reaching the limit of computational resources when no further simplifications are assumed (Kimes, 1984). In our simulations of first-order scattering we simulated the scattered rays that end at sensor positions to compare the simulations with the measurements.

The largest amount of system memory is occupied by the position and parameters of the voxels occupied by the trees. For each voxel, information such as the absorbed light intensity and the absorption coefficient has to be stored in memory for a fast computation. Increasing resolution of the voxel space increases the amount of voxels. As shown in our experimental setup the fraction of voxels representing the canopy is low. Moreover, typical tree architecture, in particular with older trees, contains large regions with no occupied voxels for example between ground and crown onset or above the canopy. Thus, an octree division of space could optimize the use of memory by dividing the space into voxels of different size. A three-dimensional region that does not contain any element of the plant structure is represented by a large cube with one parameter set, and regions containing biomass are defined by smaller voxels according to the defined resolution. The ray-tracing algorithm could be further optimized by an adaption to nonuniform voxels as discussed in Revelles et al. (2000).

\section{Possible application of the model to old-growth forest stands}

Our future goal is to apply the model to old-growth single deciduous trees in natural light conditions. For the application to natural large trees, several further steps must be included in the model. Firstly the distinction between wood and leaf material must be included. This can be done manually (Van der Zande et al., 2006; Huang and Pretzsch, 2010) or automatically if the laser scanner hardware provides additional information on the reflectivity of the surfaces that reflect the laser beam (Côté et al., 2009). Voxels containing woody material will be parametrized to have no transmissivity; the transmissivity of the leaf voxels can be set on a value that reproduces the mean PAR intensity that reaches the forest floor (Bittner et al., 2012a,b).

No laborious light measurements are therefore needed to apply the model in the field. The total intensity of incoming PAR can be provided by meteorological observation stations, and the spatial distribution in the hemisphere can be calculated using daylight distribution models (CIE, 2003). In contrast to the greenhouse light conditions the diffuse radiation of the sky will have to be included next to the direct light from the sun, because the hemisphere is typically fragmented into some hundred parcels and the light rays start at every parcel. This will increase the number of rays in comparison with the nine direct light sources in the greenhouse, but a fast computation on a single processor computer will still be possible.

This study showed that the voxel ray tracing is capable of simulating the PAR distribution in the canopy and the absorption of PAR at every voxel. In functional-structural models of forests this information is important for the calculation of the stomatal conductance of the leaves that depends sensibly on the incoming PAR. Additionally, in photosynthesis calculations the PAR regime is the most important model input. For the estimation of energy fluxes inside the canopy and between vegetation and soil this light model has to be tested and extended to handle the full electromagnetic spectrum of incoming radiation.

\section{Conclusion}

Although the model includes a rather complex representation of the canopy retrieved from TLS data, the approach 
of the ray-tracing algorithm is simply based on absorption and transmission of radiation. Despite those simplifications, the model was able to reproduce the measured regime of the visible spectrum of light of an experimental greenhouse setup of juvenile beeches. We showed that a voxel ray-tracing algorithm is a promising approach to the simulation of PAR environments in tree canopies.

In comparison with other models, which include a detailed geometrical representation of the canopy, the input parameters are easy to retrieve from laser scans of the canopy. A sensitivity analysis showed that the voxel size should be adjusted in a way that the intrinsic resolutions of the TLS data are not exceeded and should be small enough to represent the canopy structure with respect to leaf clustering and gaps. The light absorption coefficient can be calibrated by using nonspatial input data such as the mean fraction of incoming light that reaches the forest floor. The absorption constant is attached to every voxel and it is easily possible to include an absorption behavior of the leaves that is variable in space. This allows the distinction of sun leaves and shade leaves, which is often related to different physiology or nutrient status, if measurement values for the parametrization are available.

The advantage of a more complex light model such as used in our approach compared with well-known one-dimensional models is given by the spatial resolution of the light distribution within the canopy. Therefore, competition effects of neighboring trees for light or stomatal reactions of single branches and leaves can be simulated in detail by including the spatial heterogenities of the canopy. Performance tests showed that the model is able to deal with variable light input that depends on the time of the day and on meteorological conditions such as clear sky or overcast sky. The algorithm is capable of handling the amount of voxels that are necessary to represent the canopy in a sufficient way. Consequently, the coupling of our approach to a functional-structural tree model that uses the information of the light regime for the estimation of photosynthesis rates and canopy transpiration rates can be directly achieved.

However, as our current approach handles scattering of rays on leaves and other plant structures in a very simple way, the applicability of the model is restricted to PAR simulations. If the model should be used for the simulation of the total spectral intensity of the light including UV and IR, scattering effects have to be analyzed in more detail. The total wavelength spectrum is typically needed for the calculation of the energy balance in a stand as it is required in soil-atmosphere-vegetation transfer models or for simulating the distribution of UV radiation within a stand, which is the most biological reactant radiation and could have influence to the space occupation of trees.

\section{Acknowledgements}

This study was conducted in the framework of the following research projects: The role of biodiversity for biogeochemical cycles and biotic interactions in temperate deciduous forests (DFG Research Training Group 1086), Growth and Parasite Defense - Competition for Resources in Economic Plants from Forestry and Agronomy (SFB 607), and Structure and Functions of Agricultural Landscapes under Global Climate Change (PAK 346) all funded by the German Research Foundation (DFG).

\section{References}

Allen, M., Prusinkiewicz, P., and DeJong, T. 2005. Using L-systems for modeling source-sink interactions, architecture and physiology of growing trees: the L-PEACH model. New Phytologist, Vol. 166, pp. 869-880. doi: 10.1111/j.1469-8137.2005.01348.x.

Amanatides, J., and Woo, A. 1987. A fast voxel traversal algorithm for ray tracing. In: Marechal, G. (Ed.), Proceedings of Euro Graphics '87. Citeseer, Elsevier North-Holland, New York, pp. 3-10.

Baldocchi, D., and Harley, P. 1995. Scaling carbon dioxide and water vapour exchange from leaf to canopy in a deciduous forest. model testing and application. Plant, Cell \& Environment, Vol. 18, pp. 11571173. doi: $10.1111 /$ j.1365-3040.1995.tb00626.x.

Bittner, S., Janott, M., Ritter, D., Köcher, P., Beese, F., and Priesack, E. 2012a. Functional-structural water flow model reveals differences between diffuse- and ring-porous tree species. Agricultural and Forest Meteorology, Vol. 158-159, pp. 80-89. doi: 10.1016/j.agrformet.2012.02.005.

Bittner, S., Legner, N., Beese, F., and Priesack, E. 2012b. Individual tree branch-level simulation of light attenuation and water flow of three F. sylvatica L. trees. Journal of Geophysical Research, Vol. 117, No. G01037, pp. 1-17.

Bossel, H. 1996. TREEDYN3 forest simulation model. Ecological Modelling, Vol. 90, pp. 187-227. doi: 10.1016/0304-3800(95)00139-5.

Brunner, A. 1998. A light model for spatially explicit forest stand models. Forest Ecology and Management, Vol. 107, pp. 19-46. doi: 10.1016/ S0378-1127(97)00325-3.

Castro, F., and Fetcher, N. 1999. The effect of leaf clustering in the interception of light in vegetal canopies: Theoretical considerations. Ecological Modelling, Vol. 116, pp. 125-134. doi: 10.1016/S0304-3800 (98)00170-7.

Cescatti, A. 1997. Modelling the radiative transfer in discontinuous canopies of asymmetric crowns. I. Model structure and algorithms. Ecological Modelling, Vol. 101, pp. 263-274. doi: 10.1016/S0304-3800(97)00050-1.

CIE. 2003. Spatial distribution of daylight-CIE standard general sky. URL (CIE ISO15469/CIE S011/E-2003, http://www.cie.co.at)

Cohen, S., and Fuchs, M. 1987. The distribution of leaf area, radiation, photosynthesis and transpiration in a Shamouti orange hedgerow orchard. Part I. Leaf area and radiation. Agricultural and Forest Meteorology, Vol. 40, pp. 123-144. doi: 10.1016/0168-1923(87)90002-5.

Courbaud, B., de Coligny, F., and Cordonnier, T. 2003. Simulating radiation distribution in a heterogeneous norway spruce forest on a slope. Agricultural and Forest Meteorology, Vol. 116, pp. 1-18. doi: 10.1016/S0168-1923(02)00254-X.

Côté, J., Widlowski, J., Fournier, R., and Verstraete, M. 2009. The structural and radiative consistency of three-dimensional tree reconstructions from terrestrial lidar. Remote Sensing of Environment, Vol. 113, pp. 1067-1081. doi: 10.1016/j.rse.2009.01.017. 
Da Silva, D., Boudon, F., Godin, C., and Sinoquet, H. 2008. Multiscale framework for modeling and analyzing light interception by trees. Multiscale Modeling and Simulation, Vol. 7, 910 p. doi: 10.1137/ 08071394X.

Danson, F., Hetherington, D., Morsdorf, F., Koetz, B., and Allgower, B. 2007. Forest canopy gap fraction from terrestrial laser scanning. IEEE Transactions on Geoscience and Remote Sensing, Vol. 4, 157 p. doi: 10. 1109/LGRS.2006.887064.

De Pury, D., and Farquhar, G. 1997. Simple scaling of photosynthesis from leaves to canopies without the errors of big-leaf models. Plant Cell and Environment, Vol. 20, pp. 537-557. doi: 10.1111/j.1365-3040.1997. 00094.x.

Disney, M., Lewis, P., and Saich, P. 2006. 3D modelling of forest canopy structure for remote sensing simulations in the optical and microwave domains. Remote Sensing of Environment, Vol. 100, pp. 114-132. doi: 10.1016/j.rse.2005.10.003.

Gastellu-Etchegorry, J., Martin, E., and Gascon, F. 2004. DART: a 3D model for simulating satellite images and studying surface radiation budget. International Journal of Remote Sensing, Vol. 25, 73 p. doi: 10. 1080/0143116031000115166.

Gayler, S., Grams, T., Kozovits, A., Winkler, J., Luedemann, G., and Priesack, E. 2007. Analysis of competition effects in mono and mixed cultures of juvenile beech and spruce by means of the plant growth simulation model PLATHO. Plant Biology, Vol. 8, pp. 503-514. doi: $10.1055 / \mathrm{s}-2006-923979$.

Govaerts, Y., and Verstraete, M. 1998. Raytran: A Monte Carlo ray-tracing model to compute light scattering in three-dimensional heterogeneous media. IEEE Transactions on Geoscience and Remote Sensing, Vol. 36, pp. 493-505. doi: 10.1109/36.662732.

Green, S., McNaughton, K., Wunsche, J., and Clothier, B. 2003. Modeling light interception and transpiration of apple tree canopies. Agronomy Journal, Vol. 95, 1380 p. doi: 10.2134/agronj2003.1380.

Hemmerling, R., Kniemeyer, O., Lanwert, D., Kurth, W., and Buck-Sorlin, G. 2008. The rule-based language XL and the modelling environment GroIMP illustrated with simulated tree competition. Functional Plant Biology, Vol. 35, pp. 739-750. doi: 10.1071/FP08052.

Hoffmann, F. 1995. FAGUS, a model for growth and development of beech. Ecological Modelling, Vol. 83, pp. 327-348. doi: 10.1016/03043800(94)00101-8.

Huang, P., and Pretzsch, H. 2010. Using terrestrial laser scanner for estimating leaf areas of individual trees in a conifer forest. Trees Structure and Function, Vol. 24, pp. 609-619. doi: 10.1007/s00468-0100431-z.

Jupp, D., Culvenor, D., Lovell, J., Newnham, G., Strahler, A., and Woodcock, C. 2009. Estimating forest lai profiles and structural parameters using a ground-based laser called 'Echidna (R)'. Tree Physiology, Vol. 29, 171 p. doi: 10.1093/treephys/tpn022.

Kimes, D. 1984. Modeling the directional reflectance from complete homogeneous vegetation canopies with various leaf-orientation distributions. Journal of the Optical Society of America A-Optics Image Science and Vision, Vol. 1, pp. 725-737. doi: 10.1364/ JOSAA.1.000725.

Knyazikhin, Y., Mieben, G., Panfyorov, O., and Gravenhorst, G. 1997. Small-scale study of three-dimensional distribution of photosynthetically active radiation in a forest. Agricultural and Forest Meteorology, Vol. 88, pp. 215-239. doi: 10.1016/S0168-1923(97)00036-1.
Kobayashi, H., and Iwabuchi, H. 2008. A coupled 1-D atmosphere and 3-D canopy radiative transfer model for canopy reflectance, light environment, and photosynthesis simulation in a heterogeneous landscape. Remote Sensing of Environment, Vol. 112, pp. 173-185. doi: 10.1016/j. rse.2007.04.010

Lamanda, N., Dauzat, J., Jourdan, C., Martin, P., and Malézieux, E. 2008. Using 3D architectural models to assess light availability and root bulkiness in coconut agroforestry systems. Agroforestry Systems, Vol. 72, pp. 63-74. doi: 10.1007/s10457-007-9068-3.

Larsen, D., and Kershaw Jr., J. 1996. Influence of canopy structure assumptions on predictions from Beer's law. a comparison of deterministic and stochastic simulations. Agricultural and Forest Meteorology, Vol. 81, pp. 61-77. doi: 10.1016/0168-1923(95)02307-0.

Monsi, M., and Saeki, T. 1953. ber den Lichtfaktor in den Pflanzengesellschaften und seine Bedeutung für die Stoffproduktion. Japanese Journal of Botany, Vol. 15, pp. 22-52.

Moorthy, I., Miller, J., Hu, B., Chen, J., and Li, Q. 2008. Retrieving crown leaf area index from an individual tree using ground-based lidar data. Canadian Journal of Remote Sensing, Vol. 34, pp. 320-332.

Myneni, R., Ross, J., and Asrar, G. 1989. A review on the theory of photon transport in leaf canopies. Agricultural and Forest Meteorology, Vol. 45, pp. 1-153. doi: 10.1016/0168-1923(89)90002-6.

Nash, J., and Sutcliffe, J. 1970. River flow forecasting through conceptual models part I-A discussion of principles. Journal of Hydrology, Vol. 10, pp. 282-290. doi: 10.1016/0022-1694(70)90255-6.

Ni-Meister, W., Strahler, A., Woodcock, C., Schaaf, C., Jupp, D., Yao, T., Zhao, F., and Yang, X. 2008. Modeling the hemispherical scanning, below-canopy lidar and vegetation structure characteristics with a geometric-optical and radiative-transfer model. Canadian Journal of Remote Sensing, Vol. 34, pp. 385-397. doi: 10.5589/ m08-047.

Oker-Blom, P., Pukkala, T., and Kuuluvainen, T. 1989. Relationship between radiation interception and photosynthesis in forest canopies: Effect of stand structure and latitude. Ecological Modelling, Vol. 49, pp. 73-87. doi: 10.1016/0304-3800(89)90044-6.

Parveaud, C., Chopard, J., Dauzat, J., Courbaud, B., and Auclair, D. 2008. Modelling foliage characteristics in 3D tree crowns: influence on light interception and leaf irradiance. Trees - Structure and Function, Vol. 22, pp. 87-104. doi: 10.1007/s00468-007-0172-9.

Perttunen, J., Sievänen, R., and Nikinmaa, E. 2007. Proceedings of the 5th International Workshop on Functional-Structural Plant Models. Napier, New Zealand, Ch. Assessing the light environment for scots pine in the functional-structural tree model LIGNUM., pp. 59-1-59-5.

Pradal, C., Boudon, F., Nouguier, C., Chopard, J., and Godin, C. 2009. PlantGL: A Python-based geometric library for 3D plant modelling at different scales. Graphical Models, Vol. 71, No. 1, pp. 1-21. doi: 10.1016/ j.gmod.2008.10.001.

Revelles, J., Urena, C., and Lastra, M. 2000. An efficient parametric algorithm for octree traversal. Journal of WSCG, Vol. 8, pp. 212-219.

Ross, J. 1981. The radiation regime and architecture of plant stands. Dr. W. Junk Publ.: The Hague, The Netherlands.

Roupsard, O., Dauzat, J., Nouvellon, Y., Deveau, A., Feintrenie, L., SaintAndré, L., Mialet-Serra, I., Braconnier, S., Bonnefond, J., Berbigier, P., Epron, D., Jordan, C., Navarro, M., and Bouillet, J. 2008. Crossvalidating sun-shade and $3 \mathrm{D}$ models of light absorption by a tree-crop 
canopy. Agricultural and Forest Meteorology, Vol. 148, pp. 549-564. doi: 10.1016/j.agrformet.2007.11.002.

Sinoquet, H., Sonohat, G., Phattaralerphong, J., and Godin, C. 2005. Foliage randomness and light interception in 3-d digitized trees: an analysis from multiscale discretization of the canopy. Plant Cell Environment, Vol. 28, pp. 1158-1170. doi: 10.1111/j.1365-3040.2005. 01353.x.

Sinoquet, H., Stephan, J., Sonohat, G., Lauri, P., and Monney, P. 2007. Simple equations to estimate light interception by isolated trees from canopy structure features: assessment with three-dimensional digitized apple trees. New Phytologist, Vol. 175, pp. 94-106. doi: 10.1111/j.14698137.2007.02088.x.

Todd, K., Csillag, F., and Atkinson, P. 2003. Three-dimensional mapping of light transmittance and foliage distribution using lidar. Canadian Journal of Remote Sensing, Vol. 29, pp. 544-555. doi: 10.5589/m03-021.

Van der Zande, D., Hoet, W., Jonckheere, I., van Aardt, J., and Coppin, P. 2006. Influence of measurement set-up of ground-based LiDAR for derivation of tree structure. Agricultural and Forest Meteorology, Vol. 141, pp. 147-160. doi: 10.1016/j.agrformet.2006.09.007.

Van der Zande, D., Mereu, S., Nadezhdina, N., Cermak, J., Muys, B., Coppin, P., and Manes, F. 2009. 3D upscaling of transpiration from leaf to tree using ground-based LiDAR: Application on a mediterranean holm oak (Quercus ilex L.) tree. Agricultural and Forest Meteorology, Vol. 149, pp. 1573-1583. doi: 10.1016/j.agrformet.2009.04.010.
Van der Zande, D., Stuckens, J., Verstraeten, W., Muys, B., and Coppin, P. 2010. Assessment of light environment variability in broadleaved forest canopies using terrestrial laser scanning. Remote Sensing, Vol. 2, pp. 1564-1574. doi: 10.3390/rs2061564.

van Leeuwen, M., and Nieuwenhuis, M. 2010. Retrieval of forest structural parameters using LiDAR remote sensing. European Journal of Forest Research, Vol. 129, pp. 749-770. doi: 10.1007/s10342-010-0381-4.

Wang, Y. 2003. A comparison of three different canopy radiation models commonly used in plant modelling. Functional Plant Biology, Vol. 30, pp. 143-152. doi: 10.1071/FP02117.

Whitehead, D., Grace, J., and Godfrey, M. 1990. Architectural distribution of foliage in 326 individual Pinus radiata D. don crowns and the effects of clumping on radiation interception. Tree Physiology, Vol. 7, pp. 135155.

Widlowski, J., Pinty, B., Lavergne, T., Verstraete, M., and Gobron, N. 2006. Horizontal radiation transport in 3-D forest canopies at multiple spatial resolutions: Simulated impact on canopy absorption. Remote Sensing of Environment, Vol. 103, pp. 379-397. doi: 10.1016/j.rse.2006.03.014.

Wilhelms, J., and Van Gelder, A. 1992. Octrees for faster isosurface generation. ACM Transactions on Graphics, Vol. 11, pp. 201-227. doi: $10.1145 / 130881.130882$ 